\title{
O Novo Plano de Classificaçũo de Cargos
}

NEWTON MENDES DE ARAGÃO

Assistente Juridico e Professor de Cursos de Treinamento do DASP

EXPERIENCIA E OBSERVAÇÕES COLHIDAS

sificourante o último semestre do ano transato, o DASP intende suu suas atividades, notadamente na área da competência ao trein Coordenação de Aperfeiçoamento, visando, em especial, supervisãonto das equipes técnicas que se incumbirão, sob a e das e das autarquias, de proceder aos levantamentos preliminares, bem como de realizar os estudos e análises indispensáveis à implantação do novo Plano de Classificação de Cargos.

Desse modo, pôde o DASP, ao final daquele semestre, atingir seu objetivo, logrando ver treinados perto de seiscentos funcionários, na Capital da República e no Estado da Guanabara, onde ainda se concentra grande número de servidores
federais.

Note-se que o treinamento se endereçou a funcionários já especializados em pessoal, selecionados pelas equipes de alto nivel, e que acudiram à convocação, procedentes de todos os pontos do território nacional, por mais longínquos, de norte a sul, todos conscientes da importante tarefa que Ihes está reServada.

- Em se tratando de especialistas de pessoal, não se deteve técnica de classificação de cargo noções básicas da teoria de que to classificação de cargos, partindo do pressuposto minimas para o acompanhamento do curso. Em verdade, o nível 
das turmas treinadas correspondeu, em geral, à expectativa, contribuindo para o bom resultado do empreendimento.

O autor destas linhas teve oportunidade de integrar a equipe de instrutores do DASP que ministraram, em Brasilia, o referido curso de treinamento, atuando na área referente à classificação de cargos e empregos.

Seria ocioso dizer ainda da importância, do alcance, dos objetivos do referido treinamento, a esta altura já compreendidos e reconhecidos por todos nós, especialmente os que labutam, no dia-a-dia, com os problemas da classificação de
cargos.

Parece, porém, altamente conveniente, a nosso ver, que os conhecimentos ali divulgados não se circunscrevessem às equipes auxiliares e pudessem mesmo, num autêntico encadeamento, no verdadeiro sistema da "bola de neve", ser difundidos, retransmitidos em todas as áreas ministeriais ou autárincumbidos de orientar técnicos já treinados deveriam ser repartições mais distantes órgãos de pessoal regionais das tado com vistais distantes, quanto ao procedimento a ser adoNão obstante novo Plano de Classificação de Cargos. trado, pudemos fazer algumeriencia vivida durante o curso minisensejaram lições inestimáveis observações importantes que nos conclusões registradas nesteis para o futuro, bem assim as

A primeira neste trabalho.

silogismo primeira observação, válida como premissa maior de nível, em regra, elevado em nosso raciocínio, relaciona-se ao por isso mesmo incompativel a prime que recebeu treinamento, número de perguntas formuladas primeiro exame com o grande bremodo simples e outrasuladas aos instrutores, algumas soalta indagação.

Nossa perplexidade é atenuada, tendo em vista que o novo é algo de inédito e extraordinário que vai ser introduzido no tória administrativa brasileira terra, sem precedentes na hisde soluções alienígenas que e sem a importação comodista blemas nacionais. E por isso mesmo, os especialistas em pessoal, por mais
experimentados, têm dúvidas, muitas dúvidas, e formulam in-
dagações, algumas de aparên dagações, algumas de aparência simplista mas que trazem em eu bojo intensa carga de objetividade. 
Anotamos a grande maioria, senão a totalidade, das perguntas apresentadas. Muitas repetidas pelos treinandos das turmas que se sucedem, outras formuladas isoladamente, ou com pequena freqüência.

De qualquer modo, as dúvidas suscitadas pelas equipes já treinadas levam-nos, é impossivel negar, à irrecusável verdade: a grande massa dos servidores públicos civis pouco sabe do novo Plano de Classificação de Cargos.

E oportuno, portanto, a nosso ver, e nada contra-indica tal procedimento, que as respostas dadas, em aula, aos quesitos dos funcionários treinados sejam reproduzidas neste trabalho com o propósito de esclarecer, sempre e cada vez mais, o servidor público, considerando, sobretudo, o extraordinário veiculo de divulgação e penetração que é, sem dúvida alguma, a Revista do Serviço Público.

A ordem seguida é apenas a cronológica, sem preocupação de avaliar e aferir a importância das perguntas a fim de ordená-las desta ou daquela maneira.

\section{PERGUNTAS ANOTADAS COM VISTA AO
NOVO PLANO DE CLASSIFICAÇÃO DE CARGOS}

19) Por que o DASP não centraliza a implantação do novo Plano de Classificação de Cargos como o fez com o da Lei no 3.780 , de 1960 ? Seria o modo de evitar desuniformidade de critérios e prevenir possiveis distorções ou privilégios de classificação para alguns cargos.

- Porque hoje existe o Sistema de Pessoal Civil de Administração Federal criado pelo Decreto n? 67.326, de 5 de outubro de 1970, e do qual é o DASP o órgão central. Para assegurar a uniformidade de orientação dos trabalhos de elaboração e execução do Plano de Classificação de Cargos, haverá uma Equipe Técnica de alto nível, sob a presidência do dirigente do órgão de pessoal de entidade de administração direta ou indireta, que manterá com o órgão central o Sistema de Pessoal os contatos necessários para a correta elaboração e implantação do Plano.

2a) Como se farão a transposição ou transformação dos cargos atuais para as categorias funcionais a serem criadas nos chamados quadros em aberto?

sidad Serão feitas gradativamene, de acordo com as necesades e conveniências da Administração. Se ocupados, po- 
rém, os cargos, serão aplicados critérios seletivos a seus ocupantes, mediante treinamento intensivo e obrigatório.

3a) Todos serão compulsoriamente submetidos aos critérios seletivos?

- Não. Haverá direito de opção. Quem não desejar ingressar no quadro em aberto permanecerá em Quadro Suplementar, sem prejuizo de promoções e acesso.

4a) Qual o motivo da exigência indiscriminada de nova seleção para ingresso no quadro em aberto, desprezado até - fato de que muitos ingressaram no serviço público mediante concurso público realizado pelo próprio DASP?

- A Reforma Administrativa preconiza, em seus princípios básicos, a valorização, dignificação, profissionalização e aperfeiçoamento do servidor público, a par do fortalecimento do Sistema do Mérito. Para esse fim, o ingresso no quadro em aberto, que traduz, em última análise, a situação ideal objetivada pela lei da Reforma Administrativa, deverá reservar-se aos mais capazes, aos mais habilitados, aos de maior experiência.

5a) É certo que os cargos do quadro em aberto serão em número bem mais reduzido do que os atuais?

- Em verdade, o novo Plano deverá estabelecer, globalmente, nos termos das diretrizes legais vigentes, número de cargos inferior ao dos atualmente existentes. Entretanto, este número não será fixado a esmo e sim após o levantamento da chamada lotação ideal de cada unidade administrativa.

6a) Haverá concurso de provas para todos os que optarem pelo ingresso no quadro em aberto?

- Os processos seletivos serão fixados mediante decreto do Presidente da República e a seu critério, não sendo lícito se façam previsões. As soluções deverão ser, porém, uniformes; se houver exigência de prova, deverá atingir a todos, mas, em casos especiais, poderão ser precedidas de cursos intensivos de
treinamento. vantajosos?

7a) É certo que os novos vencimentos serão bem mais
ajosos?

- Dentro do princípio de que urge valorizar o servidor público, é válida a expectativa de que os vencimentos serão mais compatíveis e fixados levando em conta vários fatores inclusive em função dos salários correntes nas empresas pri-
vadas para atribuições correspondentes. 
patíveis?

8a) Quais os objetivos desses vencimentos mais combalh - Acompanhando-se as oscilações do mercado de tra, previne-se o aliciamento e a evasão de valores para as empresas particulares; incentiva-se o servidor público e criamse atrativos para a composição do quadro em aberto.

9a) O que se deve entender por plano flexivel e maleável de classificação de cargos?

- O novo Plano de Classificação de Cargos comportará sempre aprimoramento. Novos grupos, além dos dez que a lei instituiu, poderão ser criados ou desmembrados dos existentes. Este fato é que caracteriza sua flexibilidade, sua maleabilidade.

10a) A Lei no 5.645, de 10 de dezembro de 1970, delega ao Poder Executivo a faculdade de elaborar e expedir o novo Plano de Classificação de Cargos mediante decreto. Não poderá constituir a medida instrumento inconveniente, por facilitar sobremodo alterações freqüentes do Plano?

- A implantação do Plano e suas modificações, por via de decreto, serão sempre precedidas de estudos técnicos dos órgãos componentes do Sistema de Pessoal Civil, o que Ihe empresta, em tese, certa garantia contra quaisquer injunções.

11ạ) E também propósito do novo Plano contribuir para a elevação do nível de eficiência do funcionalismo?

- A resposta é afirmativa, eis que um dos objetivos últimos do novo Plano é ensejar melhores índices de eficiência na prestação dos serviços públicos para o que se instalará sistema obrigatório de treinamento dos servidores, destinado a assegurar-Ihes permanente atualização e permitindo-lhes ascensão e progressão funcionais de acordo com critérios seletivos prefixados.

12a) Não poderá haver privilégios para certas categorias funcionais prestigiosas, em face das prioridades a serem estabelecidas pelas equipes de alto nivel?

alvedriom princípio, não. As prioridades não serão fixadas ao alvedrio das equipes de alto nível. Os critérios preferenciais
inseridos na Lei no 5.645 , de 1970 , terão que ser cumpridos,
levandão prévia da reform em conta preponderantemente a implantação prévia loteforma administrativa, o estudo quantitativo e qualitativo da ação dos órgãos e a existência de recursos orçamentários suficientes. 
13a) O que objetiva a lei quando se refere a que cada "Grupo terá sua própria escala de nível"?

- Pelo Plano de Classificação de Cargos aprovado pela Lei $n$ : 3.780 , de 1960, havia uma única escala de vencimentos aplicável a todos os Grupos Ocupacionais, a todas as séries de classes e classes singulares. Hoje, por força do estatuído na Lei n: 5.645 , de 1970, deverão ser fixadas várias escalas de niveis de vencimentos, cada uma alusiva especificamente a determinado grupo de cargos, sem nenhuma correlação entre elas.

14a) É exato que a lei nova revogou o Plano de Classificação de Cargos criado pela Lei no 3.780 , de 1960 ?

- Não. O Plano então vigente foi considerado extinto. A medida que for sendo implantado o novo Plano, os cargos remanescentes passarão a constituir Quadros Suplementares destinados à supressão. Houvesse revogação expressa ou tácita por incompatibilidade entre os dois Planos, teríamos, por algum tempo, situação indefinida, até mesmo caótica, enquanto não se concretizasse a implantação do novo sistema.

15a) Que estimativa se poderá fazer quanto ao prazo necessário para a definitiva implantação do novo Plano? visto, a maleabilidade, a flexibilidade. Será, portanto, sempre
em aberto, comportanda indo da modificto, comportando constante aperfeiçoamento, criações, Cargos. Não, desmembramentos e supressões de Grupos de cluir a implantação do düentemente, a preocupação de se conao contrário atenção aos interessé seguir processos gradativos, sempre em

16a)

minado grau, virem a vimento efetivo?

- Sim. Na conformidade das razões contidas na Exposição de Motivos no 168, de 22 de outubro de 1970, assinada pelo Coordenação Geral e subma e pelo Ministro do Planejamento e Senhor Presidente da República à aprovação do Excelentíssimo lecimento de diretrizes República, em que se propôs o estabeCivil da União e Autarquias Fedassificação de cargos do Serviço recendo especial relevo as Federais, o assunto foi tratado, mematéria. Desse modo, as disposições do projeto acerca da final de sua categoria funcioncionário que ascender ao nível 
a responsabilidade das funções de direção, até determinado grau.

CONCLUSÕES

Desnecessário dizer que nenhum outro propósito nos moveu senão o de reunir, neste artigo, as considerações reputadas de maior importância, colhidas na oportunidade da realização dos recentes cursos de treinamento do DASP, visando sobretudo à maior divulgação da matéria, por sua natureza tão do interesse da numerosa classe dos servidores públicos. 


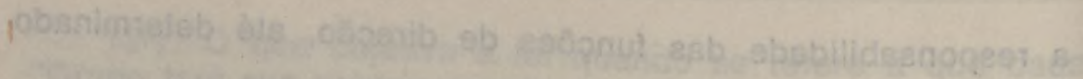

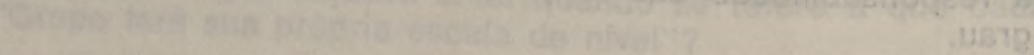
¿झ02ujonos

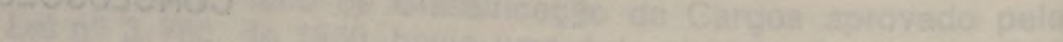

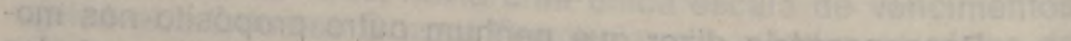

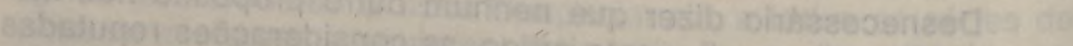

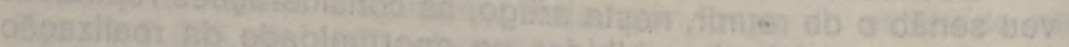

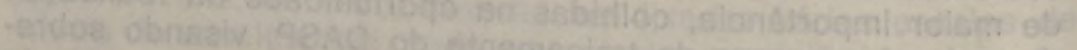

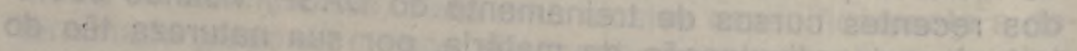

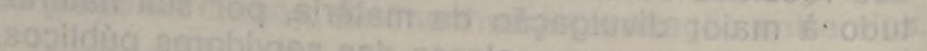

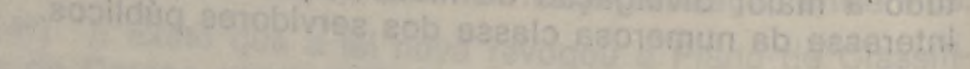

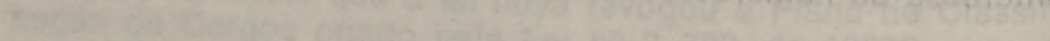

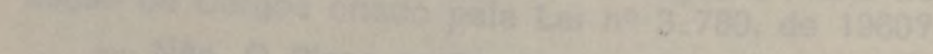

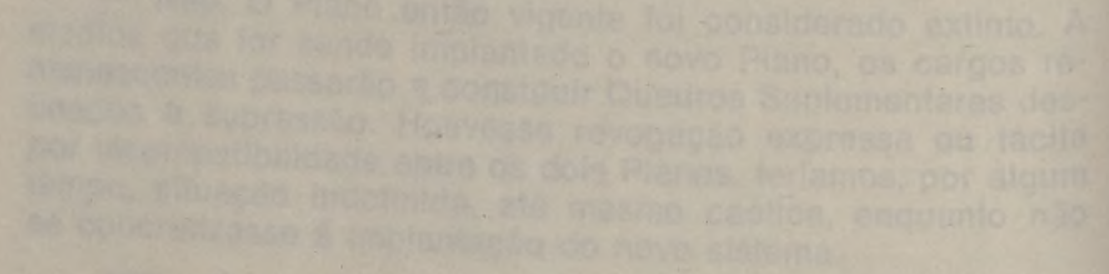

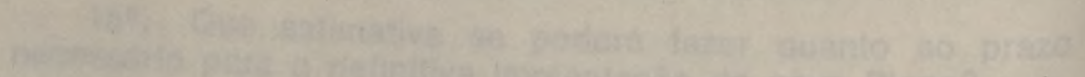

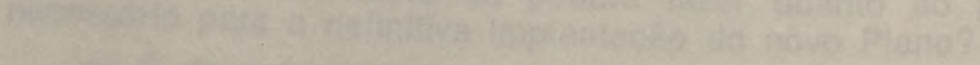

What

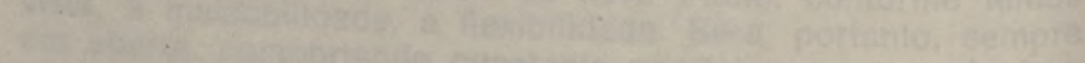

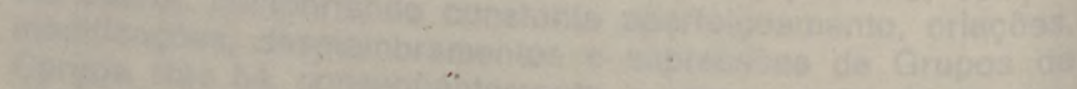

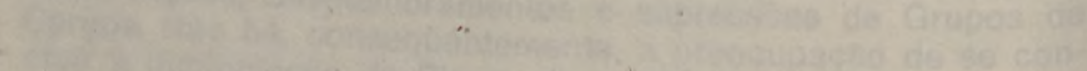
-

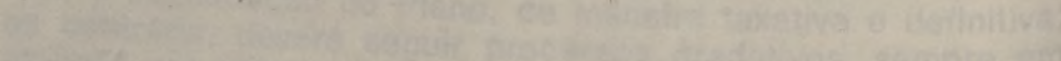

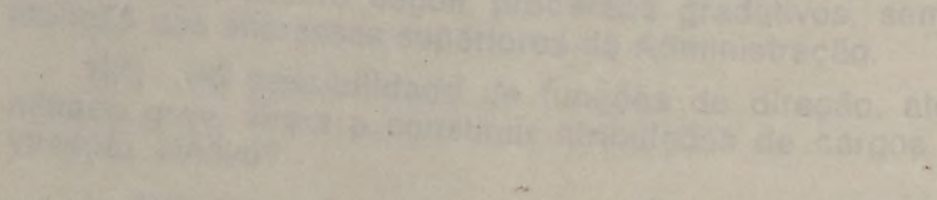

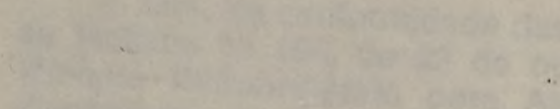

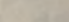

